\title{
What aspects of self do self-monitors monitor?
}

\author{
MICHELE M. TOMARELLI \\ Georgia College, Milledgeville, Georgia \\ and \\ DAVID R. SHAFFER \\ University of Georgia, Athens, Georgia
}

(Robert H. Pollack, sponsor)

\begin{abstract}
This study explored the relationships among Snyder's self-monitoring construct (and its component factors) and the three components of the Self-Consciousness Scale: public self-consciousness, private self-consciousness, and social anxiety. The best single predictor of self-monitoring tendencies was social anxiety, although the increment in R-square attributable to public selfconsciousness was also significant. Those scoring highest on the Self-Monitoring Scale were low in social anxiety and high in public self-consciousness, whereas the prototypic low self-monitoring individuals were high in social anxiety, low in public self-consciousness, and high in private self-consciousness. The data also revealed that the three presumably independent self-monitoring subscales are highly intercorrelated, a finding that calls into question their status as distinct factors.
\end{abstract}

Several years ago, Snyder (1974) developed the SelfMonitoring Scale (SMS) to assess individual differences in the extent to which people manage their behavior to create desirable or pragmatic public images. The SMS consists of 25 true-false self-descriptive statements that measure (1) concern for the social appropriateness of one's self-presentations, (2) attention to social information for cues to appropriate self-presentation, (3) the ability to control and modify one's expressive acts, and (4) the tendency to use this ability to tailor one's behavior to the situation one faces. People who score high on the SMS are called high self-monitoring individuals. They are particularly sensitive to the self-presentations of others in social situations, and they reliably use such cues as guidelines for managing their own behavior and creating an impression that is appropriate for the situation. And since the specifications for appropriate conduct vary across situations, a high self-monitoring individual frequently alters his or her socially expressive behavior and may appear to be "a different person in different situations"' (Snyder, 1979). In contrast, people who score low on the SMS (i.e., low self-monitoring individuals) have less concern for the situational appropriateness of their conduct, which seems to be guided by internal, dispositional variables (i.e., attitudes, values, etc.) that are relatively stable over time and across situations. Consequently, low self-monitoring individuals show much more cross-situational consistency of social behavior than do high self-monitoring individuals (see Snyder, 1979, and Snyder \& Monson, 1975).

The first author's mailing address is: Department of Psychology, Georgia College, Milledgeville, GA 31061.
In view of the impressive array of empirical support for the conceptual validity of Snyder's (1974) selfmonitoring construct and its influence on social behavior (see Snyder, 1979, for a review), investigators have tried to determine which of the many facets of self-monitoring might best explain these findings. Those who have factoranalyzed the SMS claim that the attribute Snyder calls selfmonitoring is divisible into three (or possibly four) factors that include acting ability, extraversion (or sociability) and other-directedness (Briggs, Cheek, \& Buss, 1980; Gabrenya \& Arkin, 1980; see also Lennox \& Wolfe, 1984). However, the items on the SMS scale that load on the extraversion factor are largely irrelevant, both conceptually and empirically, to self-monitoring behavior (see Lennox \& Wolfe, 1984), thus suggesting that both the selfmonitoring construct and its operationalization could stand to be refined.

\section{Self-Consciousness and Self-Monitoring}

One attribute that seems to overlap conceptually with self-monitoring is self-consciousness-the tendency to think about or focus attention on the self. Fenigstein, Scheier, and Buss (1975) constructed a Self-Consciousness Scale (SCS) to measure individual differences in the extent to which people habitually think about (1) their own thoughts, attitudes, values, and behaviors and (2) the reactions of other people to their self-presentations. A factor analysis of the original version of the SCS yielded a pool of 23 items constituting three orthogonal factors that were labeled private self-consciousness, public selfconsciousness, and social anxiety.

Private self-consciousness is a measure of inwardly focused attention. The private self-consciousness subscale 
consists of items such as "I'm generally attentive to my inner feelings" and "I'm constantly examining my motives," items that indicate the extent to which people attend to and reflect on their thoughts, feelings, attitudes, and other private aspects of self. Public self-consciousness is a measure of one's awareness of self as a social object that has an impact on others. The public self-consciousness subscale includes items such as "I'm concerned about what other people think of me" and "I'm concerned about the way I present myself," items that indicate the extent to which the individual is aware of how others view and react to him or her. Public and private self-consciousness thus emerged as two separate factors, implying that there are really two aspects of one's awareness of self. The third factor in the self-consciousness scale is social anxiety, a measure of the discomfort that one experiences in the presence of others. Sample items from the social anxiety subscale are "I get embarrassed very easily" and "Large groups make me nervous."

Clearly, there are conceptual parallels between private self-consciousness, public self-consciousness, and Snyder's (1974) self-monitoring construct. Like the high self-monitoring individual, those high in public selfconsciousness are concerned with presenting a desirable or pragmatic public image. Like the low self-monitoring individual, those high in private self-consciousness are likely to rely on internal dispositions, such as beliefs and values, to guide their social behavior. However, Scheier and Carver (1981) argued that Snyder's conceptualization of self-monitoring implies that an awareness of one's public self is inversely related to awareness of the private self. Admittedly, scoring of the SMS forces this dichotomy upon respondents. However, Scheier and Carver felt that this dichotomy was artificial, for the public and private subscales of the self-consciousness measurewhich bear strong resemblance to the opposite poles of the SMS-tend to be only weakly correlated, and then in a positive (rather than an inverse) direction. Thus, one has to wonder where on the self-monitoring dimension a person would fall who is high (or low) in both private and public self-consciousness.

If both public and private aspects of self contribute to self-monitoring tendencies, then the high self-monitor should be a person who is high in public selfconsciousness and low in private self-consciousness, whereas the low self-monitor should be low in public selfconsciousness and high in private self-consciousness. However, other possibilities come to mind. If attention to the private aspects of self is the factor that discriminates high and low self-monitors, then private selfconsciousness should predict self-monitoring tendencies, whereas public self-consciousness should not. On the other hand, public self-consciousness should be the best predictor of self-monitoring tendencies if the self-monitoring is primarily a measure of the person's tendency to focus attention on the self as a social object. The present study seeks to determine which of these hypotheses best describes the relationship between self-monitoring and the two components of self-focused attention.

\section{Social Anxiety and Self-Monitoring}

Is social anxiety at all related to self-monitoring tendencies? If it is, the direction of the relationship is not obvious. Snyder (1979) described the high self-monitoring individual as a consummate actor who is quite facile at assessing the character of social situations and using such information to create a desirable or pragmatic image of self. Such a portrayal seems to suggest that high selfmonitoring individuals should be at ease in social situations, comfortable around others, and, hence, low in social anxiety. Yet, as part of their attempt to correct psychometric deficiencies of Snyder's SMS, Lennox and Wolfe (1984) concluded that high self-monitors are actually high in social anxiety (as indexed by their responses to a "Fear of Negative Evaluation scale"). Unfortunately, Lennox and Wolfe were working with a drastic revision of Snyder's original instrument, and there are no assurances that their results hold for self-monitoring as measured by Snyder's scale. Moreover, a fear of negative evaluations seems somewhat removed from (and is perhaps even orthogonal to) the generalized sense of social discomfort (e.g., nervousness, embarrassment) measured by the social-anxiety factor of the SCS. Thus, a second purpose of the present study was to explore the relationship between self-monitoring propensities and the general disposition to be anxious or discomforted in social situations.

\section{METHOD}

Participants were 310 introductory psychology students who completed Snyder's (1974) SMS and the SCS (Fenigstein et al., 1975) as part of a large group-testing session. Each participant's responses to the SMS were totaled to provide an overall self-monitoring score, and then partitioned into the three factors or subscales (acting ability, extraversion, and other-directedness) that emerged from Brigg's et al. (1980) factor analysis of this instrument. Responses to the SCS yielded three scores for each participant: public self-consciousness, private self-consciousness, and social anxiety.

\section{RESULTS AND DISCUSSION}

The correlations of the SMS and its subscales with the three components of the SCS are presented in Table 1. Subscales from both instruments were also intercorrelated as a check on the presumed independence of these factors. ${ }^{1}$

\section{On the Presumed Independence of the Self-Monitoring and the Self-Consciousness Factors}

An examination of Table 1 reveals that each of the selfmonitoring subscales was significantly correlated with the overall self-monitoring scores. Moreover, the intercorrelations among these three presumably independent factors are not only positive and significant (ranging from +.36 to +.75$)$, but are also generally greater than the 
Table 1

Correlations Among the Self-Monitoring Scale and its Factors and the Three Components of the Self-Consciousness Scale

\begin{tabular}{lllllrrr}
\hline \multicolumn{1}{c}{ Measure } & SM & E & A & \multicolumn{1}{c}{ OD } & \multicolumn{1}{c}{ PRSC } & \multicolumn{1}{c}{ PUSC } & \multicolumn{1}{c}{ SA } \\
\hline Self-Monitoring (SM) & & $.28 *$ & $.40^{*}$ & $.42^{*}$ & .17 & $.24 *$ & $-.29 *$ \\
Extraversion (E) & & & $.75^{*}$ & $.60^{*}$ & -.11 & -.01 & -.14 \\
Acting Ability (A) & & & & $.36 *$ & .05 & .02 & -.16 \\
Other-Directedness (OD) & & & & & -.07 & .12 & .08 \\
Private Self-Consciousness (PRSC) & & & & & & $.42 *$ & -.02 \\
Public Self-Consciousness (PUSC) & & & & & & & $.21^{*}$
\end{tabular}

Social Anxiety (SA)

Note $-n=310 . \quad{ }^{*} p<.001$.

correlations between each of the subscales and the total self-monitoring scores. Clearly, these data cast some doubt on the notion (see Briggs et al., 1980) that the three self-monitoring subscales should be treated as distinct factors.

The analysis of the self-consciousness subscales also produced two significant intercorrelations. First, the correlation between public and private self-consciousness was positive and substantially greater $(+.42)$ than those $(+.20$ to +.25$)$ reported in earlier research (see Scheier \& Carver, 1981). Moreover, public self-consciousness was positively correlated with social anxiety $(r=.21$, $\mathrm{p}<.001)$.

\section{Self-Monitoring and Self-Consciousness}

The relationships that emerged between self-monitoring and the three components of self-consciousness were interesting and unexpected. Although both public and private self-consciousness were positively correlated with self-monitoring scores, the subscale that best predicted subjects' self-monitoring tendencies was social anxiety. Note that the correlation between social anxiety and selfmonitoring is negative, thus supporting Snyder's (1974) view that self-monitoring individuals tend to be "at ease" or at least relatively comfortable in social situations. A stepwise multiple regression of the three selfconsciousness scales on self-monitoring scores revealed that both social anxiety and public self-consciousness were reliable predictors of self-monitoring tendencies, but that the increment in R-square attributable to private selfconsciousness was not significant.

Table 2

Mean Self-Monitoring Scores of Subjects Above and Below the Median in Social Anxiety, Public Self-Consciousness (PUSC), and Private Self-Consciousness (PRSC)

\begin{tabular}{lccccc}
\hline & \multicolumn{4}{c}{ Social Anxiety } \\
\cline { 2 - 4 } & \multicolumn{3}{c}{ Low } & \multicolumn{2}{c}{ High } \\
\cline { 2 - 4 } \cline { 5 - 6 } PRSC & Low & High & Low & High \\
\hline Low & 12.42 & 14.48 & 11.88 & 12.44 \\
& $(n=43)$ & $(n=23)$ & $(n=42)$ & $(n=68)$ \\
High & 13.81 & 15.47 & 9.89 & 12.83 \\
& $(n=21)$ & $(n=51)$ & $(n=27)$ & $(n=35)$ \\
\hline
\end{tabular}

Note: Grand mean self-monitoring $=12.92 ;$ median $=13$.
The relationship between social anxiety and selfmonitoring is graphically illustrated in Table 2 . There we see that people who are low in social anxiety tend to score above the sample mean in self-monitoring, particularly if they are also high in public self-consciousness. In contrast, all groups above the median in social anxiety scored below the sample mean in self-monitoring, with the prototypic low self-monitor being the socially anxious individual who is low in public self-consciousness and high in private self-consciousness.

\section{CONCLUSIONS}

The most interesting finding to emerge from this study was that the social-anxiety factor of the SCS was a better predictor of self-monitoring tendencies than either public or private self-consciousness (although, as anticipated, high self-monitoring individuals did tend to score high in public self-consciousness). Apparently, Snyder (1974) is correct in characterizing the high self-monitor as one who is at ease in social situations and particularly concerned about the appropriateness of his or her social behavior. On the other hand, those scoring very low in selfmonitoring were socially anxious individuals who were in touch with their feelings, attitudes, and values, and at the same time, largely unaware of or unconcerned with the images they project-a profile that is quite similar to the verbal description of low self-monitors provided by Snyder (1979).

Despite the significant relationships that emerged between selfmonitoring and the self-consciousness subscales, we can hardly claim to have captured the essence of the self-monitoring construct. Indeed, the three self-consciousness subscales (and their interactions) produced a multiple $\mathrm{R}$ of .48 , thus accounting for only about $23 \%$ of the variability in subjects' self-monitoring scores. So what does the SMS really measure? This study provides some interesting and important clues, but no truly definitive answers.

\section{REFERENCES}

Briggs, S. R., Cheek, J. M., \& Buss, A. H. (1980). An analysis of the self-monitoring scale. Journal of Personality and Social Psychology, 38, 679-686.

Fenigstein, A., Scheier, M. F., \& Buss, A. H. (1975). Public and private self-consciousness: Assessment and theory. Journal of Clinical and Consulting Psychology, 43, 522-527.

Gabrenya, W. K., JR., \& ARKIN, R. M. (1980). Self-Monitoring Scale: Factor structure and correlates. Personality and Social Psychology Bulletin, 6, 13-22.

Lennox, R. D., \& Wolfe, R. N. (1984). Revision of the SelfMonitoring Scale. Journal of Personality and Social Psychology, 46, 1349-1364.

SCheier, M. F., \& Carver, C. S. (1981). Private and public aspects of self. In L. Wheeler (Ed.), Review of personality and social psychology (Vol. 2). Beverly Hills, CA: Sage. 
SNYDER, M. (1974). Self-monitoring of expressive behavior. Journal of Personality and Social Psychology, 30, 526-537.

SNYDER, M. (1979). Self-monitoring processes. In L. Berkowitz (Ed.), Advances in experimental social psychology (Vol. 12). New York: Academic Press.

SNyder, M., \& Monson, T. C. (1975). Persons, situations, and the control of social behavior. Journal of Personality and Social Psychology, 32, 637-644.

\section{NOTE}

1. Since the results of all analyses were comparable for males and females, we have collapsed across gender and presented only those outcomes for the sample as a whole.

(Manuscript received for publication October 22, 1984.) 